\title{
Erratum to: The gamut of primary retroperitoneal masses: multimodality evaluation with pathologic correlation
}

\author{
Guillermo P. Sangster, ${ }^{1}$ Matias Migliaro, ${ }^{2}$ Maureen G. Heldmann, ${ }^{3}$ Peeyush Bhargava, ${ }^{3}$ \\ Alireza Hamidian Jahromi, ${ }^{4}$ Jaiyeola Thomas-Ogunniyi ${ }^{5}$ \\ ${ }^{1}$ Departments of Radiology and Anesthesiology, LSU Health - Shreveport, 1501 Kings Highway, Shreveport, LA 71103, USA \\ ${ }^{2}$ Hospital Santa Isabel de Hungria, Mendoza 5521, Argentina \\ ${ }^{3}$ Department of Radiology, LSU Health - Shreveport, 1501 Kings Highway, Shreveport, LA 71103, USA \\ ${ }^{4}$ Department of Surgery, LSU Health - Shreveport, 1501 Kings Highway, Shreveport, LA 71103, USA \\ ${ }^{5}$ Department of Pathology, LSU Health - Shreveport, 1501 Kings Highway, Shreveport, LA 71103, USA
}

\section{Erratum to: Abdom Radiol (2016) 41:1411-1430 DOI 10.1007/s00261-016-0735-6}

The original version of this article unfortunately contained a mistake. The author name Alireza Hamidian should read as Alireza Hamidian Jahromi. It is now corrected.

The online version of the original article can be found under doi:10.1007/s00261-016-0735-6.

Correspondence to: Guillermo P. Sangster; email: gsangs@1suhsc.edu 